\title{
Atuação dos conselhos gestores do município de Viçosa-MG no enfrentamento da pandemia da Covid-19
}

A pandemia da Covid-19 desencadeou crise global que reclama atuação sem precedentes dos poderes constituídos no Brasil. Para além das mazelas da máquina pública de saúde do país, o evento descortina a grave crise federativa e de representatividade que dificulta uma nação genuinamente democrática. Nesse contexto, interessa o estudo dos conselhos gestores de políticas públicas, representantes da gestão participativa na incessante busca pela realização dos interesses da coletividade. Assim, o presente estudo busca analisar a atuação dos Conselhos Gestores do município de Viçosa-MG no enfrentamento da pandemia da Covid-19. Especificamente pretende-se: identificar e descrever as ações para o enfrentamento da pandemia por parte desses Conselhos; compreender se as ações são efetivas; e identificar os desafios para os conselhos neste momento, sob o olhar dos entrevistados. Para tanto, parte-se de uma contextualização acerca da participação e controle social no âmbito brasileiro, rematando no sentido da essencialidade de mecanismos de participação popular para o aprimoramento do regime democrático. acerca da participação e controle social no âmbito brasileiro, rematando no sentido da essencialidade de mecanismos de participação popular para o aprimoramento do regime democrático. Seguindo-se com as conceituações dos conselhos gestores e das complexidades de sua atuação, tais como desenho institucional, representação, relações de poder, assimetria informacional
e da participação. Os conselhos gestores em análise, guardadas as especificidades de suas áreas, são paritários e têm promovido ações no enfrentamento da pandemia, como atendimento e suporte à saúde a pacientes suspeitos e diagnosticados com Covid-19; realização de campanhas educativas de terientação e conscientização e campanhas solidárias. Embora a percepção de efetividade das ações tenha se apresentado quase consensual entre os entrevistados, foram sinalizados desafios relacionados a representatividade, escassez de recursos, intersetorialidade, participação social, dentre outros. Concluiu-se, por fim, que os conselhos devem se direcionar através de esforços coordenados, mirando alinhar sua atuação com a do governo, de modo a romper com a intersetorialidade e assegurar o cumprimento de seu papel na aproximação entre poder público e comunidade. Constatou-se, igualmente, a precisão de canais mais amplos e versáteis de comunicação e de prestação de contas, de otimização na utilização de recursos, bem como de capacitação de seus membros, preparando-os para o enfrentamento das crises emergenciais que hão de surgir.

Palavras-chave: Democracia social; Conselhos gestores; Covid-19.

\section{Performance of the management councils of the municipality of Viçosa-MG in coping with the pandemic of Covid-19}

\begin{abstract}
The Covid-19 pandemic started a global crisis that demands unprecedented action by the constituted powers in Brazil. In addition to the problems of the country's public health system, the The Covid-19 pandemic started a global crisis that demands unprecedented action by the constituted powers in Brazil. In addition to the problems of the country's public health system, the event reveals the serious federative and representativeness crisis that difficulties a genuinely democratic nation. In this context, the study of public policy management councils,
representatives of participatory management in the continuous search of the collective interests. Thus, the present study seeks to analyze the performance of the Management Councils of representatives of participatory management in the continuous search of the collective interests. Thus, the present study seeks to analyze the performance of the Management Councils of
the municipality of Viçosa-MG in confronting the Covid-19 pandemic. Specifically, our aim is to: identify and describe the actions to tackle the pandemic by these Councils; understand if the actions are effective; and to identify the challenges for the councils at this moment, in the opinion of the interviewees. For that, it starts from a contextualization about participation and social control in the Brazilian context, concluding in the sense of the essentiality of mechanisms of popular participation for the improvement of the democratic system. After, presents the concepts of the management councils and the complexities of their performance, such as institutional design, representation, power relations, information asymmetry and participation. The management councils, keeping in mind the specificities of their areas, are on an equal footing and have promoted actions in the confrontation of the pandemic, such as health care and support to suspected and diagnosed patients with Covid-19; educational guidance and awareness campaigns and solidarity campaigns. Although the perceived effectiveness of the actions was al cost con was concluded that the councils shoud focus on coordinated effort, aing to align their peformance with that of the government, in order to break with the intersectorality and ensure the fulfillment of their role in bringing government and community closer together. The precision of broader and more versatile channels of communication and accountability, of optimizing the use of resources, as well as of training its members, preparing them to face the emergency situations that will arise.
\end{abstract}

Keywords: Social democracy; Management councils; Covid-19.

Topic: Gestão Pública

Reviewed anonymously in the process of blind peer.
Received: 07/01/2021

Approved: 22/03/2021
Dayse Leticia Pereira Amâncio (it

Universidade Federal de Viçosa, Brasil

http://lattes.cnpq.br/9998598879957550

http://orcid.org/0000-0002-5736-0141

leticia.dayse@gmail.com

Ebio Viana Meneses Neto (ib

Universidade Federal de Viçosa, Brasil

http://lattes.cnpq.br/2466741960251472

http://orcid.org/0000-0002-0909-1784

ebio.meneses1990@gmail.com

\section{Simone Martins (iD)}

Universidade Federal de Viçosa, Brasil

http://lattes.cnpq.br/5311862771207808

http://orcid.org/0000-0002-6614-4811

smabreu@ufv.br

\section{Referencing this:}

AMÂNCIO, D. L. P.; MENESES NETO, E. V.; MARTINS, S.. Atuação dos conselhos gestores do município de Viçosa-MG no enfrentamento da pandemia da Covid-19. Revista Brasileira de Administração Científica, v.12, n.1, p.170-185, 2021. DOI: http://doi.org/10.6008/CBPC2179$\underline{684 X .2021 .001 .0014}$

DOI: 10.6008/CBPC2179-684X.2021.001.0014 


\section{INTRODUÇÃO}

Em dezembro de 2019, casos de pneumonia de origem desconhecida foram identificados em Wuhan, capital da província de Hubei na China. Tais casos foram associados a um novo RNA vírus como patógeno responsável, atualmente denominado SARS-CoV 2 ou Coronavírus, e causador da doença denominada COVID-19, cuja pandemia foi declarada em março de 2020 pela Organização Mundial da Saúde (OMS).

Impactos, até então conhecidos, causados pelo movimento pandêmico evidenciam que o mundo não se encontrava preparado para tal panorama, vivenciando implicações de naturezas tanto sanitárias, quanto sociais e econômicas. Em que pese a conjecturada ação do Estado nas mais diversas frentes, há que se destacar a necessidade de coordenação de ações multidimensionais que reclamam soluções intersetoriais capazes de unir poder público, iniciativa privada e sociedade civil em esforços para enfrentar a pandemia e seus efeitos (SCHMIDT et al., 2020).

A exemplo do caso brasileiro, nota-se uma fragilidade estrutural que favoreceu a instauração da crise sanitária, desvelando o tensionamento político motivador de frequentes conflitos entre as unidades federadas. Dessa forma, a falta de alinhamento entre os entes políticos, bem como notadas ações extemporâneas do governo federal, impõem dificuldades aos governos estaduais e locais na adoção de medidas protetivas e de enfrentamento da Covid-19, especialmente no que tange ao atendimento das demandas da coletividade. Ainda que se note, no âmbito do governo federal, uma agenda de assistência para a população em situação de vulnerabilidade e medidas para garantir a vitalidade de pequenas e médias empresas, a todo momento os jornais de grande circulação veiculam a dificuldade de a sociedade e empresários acessarem os benefícios, além de se observar uma desorientação para a sociedade brasileira.

Já no âmbito estadual, a partir da confirmação de casos em vários municípios do Estado de Minas Gerais, e da heterogeneidade das regiões mineiras quanto a aspectos epidemiológicos e assistenciais, o plano contingencial balizou-se na especificidade de cada território, de forma que as ações partiram de acordo com o número de casos, da situação demográfica e do complexo hospitalar de cada município. Ainda nesse contexto, a Secretaria de Estado de Saúde de Minas Gerais, por meio da Resolução SES/MG no 7.011, de 30 de janeiro de 2020, instituiu o Centro de Operações de Emergência em Saúde (COES), com caráter emergencial e consultivo, para resposta técnica e efetiva à calamidade pública instaurada.

No âmbito municipal, mais especificamente na cidade de Viçosa - MG, também são encontrados desafios. Em função da grande população idosa e rural, as barreiras sanitárias nas divisas territoriais se tornaram a primeira grande medida tomada pela municipalidade. Para traçar planos de ação, foi criado o Centro de Operações de Emergência em Saúde (COES-Viçosa) que - vinculado ao gabinete do Prefeito representa um comitê extraordinário de caráter consultivo. As ações do COES são embasadas em critérios técnicos e levam em consideração toda a logística do SUS e as orientações dos órgãos nacionais de saúde.

É imprescindível que as ações entre os entes federados sejam coordenadas, de forma a garantir a efetividade das políticas desenvolvidas e o alinhamento entre união, estados, distrito federal, municípios, devendo ser claro o papel incumbido a cada um. À União cabe a formulação de regras e ações gerais; os 
estados respondem pela adaptação das medidas para a particularidade de cada região; e aos municípios cabe a proposição de normativas e estratégias que compreendam a especificidade relativa a cada um deles.

Isto posto, a pandemia da Covid-19 impõe uma situação desafiadora, devido a imprevisibilidade dos impactos da doença, que estabelece uma nova lógica para as diversas organizações e para o Estado, e requer a união de esforços entre governo e sociedade para superar os inúmeros desafios dos momentos atual e póscrise. Neste contexto, a participação e o controle social se tornam ainda mais relevantes e necessários, seja para aproximar a sociedade dos gestores públicos, intensificando o controle sobre as suas ações, ou para agir de forma propositiva na construção de uma agenda coletiva que vise amenizar os efeitos do cenário que se desenha e/ou oportunizar soluções para o seu enfrentamento.

Dentre os mecanismos para viabilizar tal participação e controle social, têm destaque os conselhos gestores de políticas públicas, os quais são considerados importantes aparatos na busca da realização do estado democrático em função de representarem elos essenciais entre a sociedade civil e os governantes. Assim, considerando o atual contexto, eles podem contribuir para demandas que se iniciem na sociedade civil, gerem proposições na apresentação de soluções para o poder público e acarretem ações que possam induzir a redução dos riscos e impactos causados pela pandemia. No âmbito de vigilância em saúde, por exemplo, destaca-se a capacidade de subsidiar o controle sanitário, epidemiológico, ambiental e também da saúde do trabalhador.

Não obstante a atuação que se espera de tais conselhos, suas realidades são normalmente permeadas por diversos desafios. Eis que neste cenário de pandemia da Covid-19 - o qual tende a gerar reações e comportamentos pautados pela sensação de caos e pânico na população - os desafios se intensificam e se torna imprescindível promover adaptações nos processos de acompanhamento tanto das demandas da comunidade quanto das ações governamentais sendo, ainda, propositivos na apresentação de soluções para o poder público que, eventualmente, propiciem o êxito das medidas adotadas no enfrentamento da pandemia (SCHMIDT et al., 2020).

Ante o exposto, o presente estudo teve como objetivo geral analisar a atuação dos Conselhos Gestores Viçosenses no enfrentamento da pandemia da Covid-19 e, mais especificamente, pretendeu-se: I. Identificar e descrever as ações para o enfrentamento da pandemia provocada pela Covid-19, por parte dos Conselhos Municipais de Viçosa; II. Compreender se as ações são efetivas; e III. Identificar, sob o olhar dos entrevistados, os desafios que se apresentam, e/ou se intensificam, para os conselhos neste momento. Para tanto, buscou-se compreender as seguintes questões: como os Conselhos Gestores Viçosenses têm atuado para o enfrentamento da pandemia da Covid-19? E como ela tem afetado o contexto dessas instituições?

Cabe pontuar a relevância de se considerar as promessas de avanços intrínsecas à atuação dos conselhos, associadas aos notáveis e inegáveis impactos da pandemia nas mais diversas frentes, para que potenciais avanços sejam vislumbrados nas discussões acerca de participação e controle social. A relação entre tais temas se torna primordial para que se possa verificar os reflexos na atuação das aludidas instituições e, por consequência, vislumbrar a necessidade de adequações e melhorias alusivas há tempos de crise e que, eventualmente, possam e devam ser incorporadas em caráter permanente. 
Este artigo relata um estudo de caso, cujo propósito consistiu em uma abordagem da atuação dos conselhos gestores de políticas públicas do município de Viçosa-MG, sob o enfoque da pandemia da Covid19, que trouxe consigo uma crise global sem precedentes. Assim, além desta introdução, o texto está dividido em quatro seções: na seção 2 são reunidas contribuições da literatura sobre participação e controle social e sobre conselhos gestores de políticas públicas; a seção 3 traz luz aos procedimentos metodológicos utilizados; na seção 4 apresenta-se uma análise da atuação dos Conselhos Gestores do município de ViçosaMG no enfrentamento da pandemia e, por fim, na seção 5, são tecidas considerações finais.

\section{REVISÃO TEÓRICA}

\section{Participação e controle social}

De forma geral, as ações governamentais estão sujeitas ao controle público, seja ele institucional ou social. O primeiro, previsto nos artigos 70 e 71 da Constituição Federal de 1988, é formado por instituições internas (ouvidorias e os setores de controle interno, como a Controladoria-Geral da União) e externas (os Tribunais de Contas). Já o controle social, que é a participação da sociedade na gestão de políticas e programas promovidos pelo Governo Federal, visa a democratização dos processos decisórios (BRASIL, 1988).

Em consonância com o que é apresentado na Constituição Federal de 1988, Arantes et al. (2010) diz que o controle explica, no sentido puro da palavra, o ciclo da representação política. $\mathrm{O}$ autor complementa relatando que tal ciclo termina quando o povo, em consonância com as situações de controle, é capaz de avaliar criticamente se os governantes os representam de fato e assim, a partir do momento político, decidir pela manutenção ou retirada deles.

A partir dos conceitos de democracia participativa, pode-se dizer que os movimentos sociais explicam, de uma nova forma, as ideias em torno da participação e controle social. Ou seja, existe uma luta e um desejo de expressar-se numa nova cidadania, fazendo com que, a partir do ideal coletivo, a sociedade civil se transforme em sociedade política (NOBRE, 2007).

Nesse sentido, Menezes (2005) afirma que a participação da sociedade civil nas políticas públicas propostas por atores governamentais aparece como forma de validá-las, para que a democracia participativa e as tomadas de decisão do Estado possam caminhar juntas. Assim, os governos que ideologicamente incentivem a participação dos cidadãos na formulação e implementação de políticas públicas, tornam-se mais eficientes do que aqueles puramente técnicos.

No tocante à referida participação, a efetividade deliberativa ganha destaque ao provocar complexas discussões. Assim como o cálculo de indicadores que envolvem diversas variáveis e como a eficiência ou a eficácia, a ideia de efetividade busca expressar, em várias dimensões, ideias como inclusão deliberativa ou a capacidade de expressão da sociedade civil (VAZ, 2011). Cunha (2004) complementa dizendo que a efetividade deliberativa estaria expressa nos "procedimentos pelos quais os grupos sociais se mantêm nas organizações e conseguem, com o tempo, fornecer estruturas de comportamento com o foco principal no 
controle sobre as ações governamentais".

Entretanto, embora necessários, as ações de controle interno, somente, não são suficientes para garantir a efetividade, a eficiência e a eficácia do serviço público, menos ainda que este sirva a sociedade civil baseada nas normas de um governo democrático (CAMPOS, 1990). Campos (1990) ainda complementa que:

A economia de recursos públicos, a eficiência e a honestidade requerem atenção especial, mas há outros padrões de desempenho que merecem consideração: qualidade dos serviços; maneira como tais serviços são prestados; justiça na distribuição de benefícios, como também na distribuição dos custos econômicos, sociais e políticos dos serviços e bens produzidos; grau de adequação dos resultados dos programas às necessidades das clientelas. (CAMPOS, 1990)

Neste sentido, Wampler (2011) discute sobre a ideia de governança participativa, afirmando que está fornece novos modos de relação entre Estado e sociedade civil, tendo em vista a falta de credibilidade de outros dois mecanismos responsáveis por manter essa ligação: O Poder Legislativo e o sistema partidário. 0 Poder Legislativo por ser significativamente subordinado ao poder Executivo e o sistema partidário por não ser representativo, ou seja, a sociedade civil não entende os partidos como a extensão dos seus anseios.

Nesta seara, os líderes da sociedade civil são de suma importância para fortalecer o elo entre os cidadãos comuns e as autoridades governamentais, de forma que a participação cidadã auxilie para o desenvolvimento de programas e serviços, além de conceber controle aos recursos controlados pelo Estado (WAMPLER, 2011). De fato, no início da década de 90, Campos (1990) já tinha essa visão quando afirmava que "uma sociedade precisa atingir um certo nível de organização de seus interesses públicos e privados, antes de tornar-se capaz de exercer controle sobre o Estado".

Assim, em busca da eficácia e da eficiência nos processos públicos, pode-se dizer que "controle é, portanto, momento constitutivo do processo mais amplo de accountability ${ }^{1}$ ou responsabilização política dos governantes para garantir (ou tentar garantir) que eles atuem, de fato, como representantes do povo" (ARANTES et al., 2010). Arantes et al. (2010) acrescentam, ainda, que o controle social é uma forma de accountability vertical que trabalha de forma contínua e vai além do período eleitoral. Esta deve funcionar como incremento ao controle exercido pelos clássicos mecanismos de responsabilização: Consulta Popular, Conselhos, Orçamentos Participativos e Parcerias com ONG's.

De fato, o controle social e a democracia participativa se valem de características parecidas para manter a qualidade, que perpassam pela informação e debate entre os cidadãos, pelas instituições fiscalizadoras e principalmente por leis que validem a heterogeneidade da sociedade e vetem os privilégios das lideranças (ARANTES et al., 2010). Neste sentido, Rocha (2008) pontua que o processo constitucional avançou no formato das políticas sociais, tendo sido condição determinante para validar a criação de espaços efetivos de participação da sociedade civil nos projetos de políticas públicas. Como exemplo dos aludidos espaços, tem-se os Conselhos Gestores, adiante abordados.

\footnotetext{
${ }^{1}$ Desde os estudos de Campos (1990) sobre o termo Accountability, verifica-se que a estrutura política brasileira mudou gradualmente: vários aspectos da Constituição Federal estão em pleno gozo legal, a democracia está consolidada e várias foram as reformas propostas pelos órgãos deliberativos estatais, entre as quais está o desaparelhamento dos Estados e municípios, sendo os espaços deliberativos do último o foco deste trabalho (PINHO et al., 2009).
} 


\title{
Conselhos gestores de políticas públicas
}

A despeito de a história política brasileira, conforme assevera Rocha (2008), ter sido "repleta de exemplos de manifestações populares que demonstram a capacidade do povo brasileiro se organizar e lutar por seus direitos" (ROCHA, 2008), podemos considerar como marco dos mecanismos de participação nos processos decisórios, a Constituição Federal de 1988.

Diante dos avanços constitucionais no desenho das políticas sociais, foram criados espaços concretos de participação da sociedade, tanto no planejamento, quanto na execução de políticas. Assim, dentre os mecanismos instituídos, os conselhos gestores de políticas públicas se destacam por participar ativamente no relacionamento entre atores governamentais e sociedade civil. De fato, "a participação cidadã tornou-se um pilar muito importante nessa relação, pois pressupõe o compartilhamento de responsabilidades de forma sistematizada num ambiente contraditório" (PEREIRA et al., 2016).

Na definição de Carneiro (2002), os Conselhos Gestores de Políticas Públicas representam:

\begin{abstract}
Canais de participação política, de controle público sobre a ação governamental, de deliberação legalmente institucionalizada e de publicização das ações do governo. [...] os conselhos, como espaços de formação das vontades e da opinião, são também mecanismos de ação, que inserem na agenda governamental as demandas e os temas de interesse público, para que sejam absorvidos, articulados politicamente e implementados sob a forma de políticas públicas. Portanto, mais do que um canal comunicacional para ressonância das demandas sociais, os conselhos possuem dimensão jurídica e têm poder de tornar efetivas as questões, os valores e os dilemas vivenciados no espaço da sociedade civil. (CARNEIRO, 2002)
\end{abstract}

Tais Conselhos, de caráter híbrido e paritários, são fóruns altamente institucionalizados, organizados e regulados, legalmente e administrativamente, em diversas esferas de poder - âmbitos municipais, estaduais e federais - e em cada área de política pública, sendo seus participantes representantes de grupos de interesses específicos das aludidas áreas. Por esta razão, seu papel institucional acaba por depender, consideravelmente, da área a que estão relacionados (CORTES, 2011).

Ademais, Carneiro (2002) destaca que os conselhos não podem ser considerados meros locais informais de comunicação, vez que a mencionada composição paritária, entre membros governamentais e não-governamentais, e seu caráter constitucional, os definem como parte do Estado, com todos os perigos e dilemas inerentes a esse status.

No contexto da complexidade desses espaços, Faria et al. (2011) abordam o desenho institucional como fator de impacto em seu desempenho, por definir questões relacionadas, por exemplo, a institucionalização dos conselhos, ao potencial inclusivo e democratizante, à composição e representação em seu interior, à dinâmica em seu processo decisório e à publicização das ações. Dessa forma, é imprescindível analisar quem participa dos processos e quem possui maiores condições para se expressar e influenciar nas decisões - com especial atenção às informações sobre quem pode presidir os conselhos e os poderes que esse cargo concentra.

Fonseca (2011) corrobora quanto à importância do desenho institucional nas relações de poder, mas considera seu enfoque insuficiente. Assim, o autor traz luz à análise da concentração de poder sob a ótica das relações sociais, considerando os interesses, tanto econômicos quanto políticos, que possam ter 
motivado a criação desses espaços e que possam afetar seu funcionamento, e ressalta que:

Na busca por minorar essa concentração de poder, os analistas frequentemente pregam a necessidade da paridade numérica entre conselheiros governamentais e a sociedade civil e de um desenho institucional que tenha mecanismos de limitação do poder governamental, como eleições livres para conselheiros e/ou eleições para a presidência. (FONSECA, 2011)

Ainda na seara da complexidade dos conselhos, tem-se o problema da assimetria informacional, vez que a disponibilidade e o acesso à informação por vezes são restritos à discricionariedade do governo, além do problema da assimetria da participação, a qual advém da forma de seleção dos representantes e da capacidade de intervenção diversa dos mesmos (CARNEIRO, 2002). Borba (2011) complementa que as configurações dessas instituições acabam por afetar suas capacidades de atrair diferentes públicos, oferecendo oportunidades distintas de participação política para os diferentes segmentos sociais.

Não obstante as aludidas assimetrias, Carneiro (2002) destaca, ainda, a necessidade de mecanismos institucionalizados de controle e do uso de instrumentos que permitam a efetivação da dimensão deliberativa, para que a eficácia dos conselhos não dependa apenas das oportunidades de participação e deliberação abertas pelo Estado. Em se tratando especificamente da atuação do Estado, Rocha (2008) expõe que o principal desafio reside justamente em investir em sua capacidade de fazer frente à quantidade expressiva de novas (e antigas) demandas que adentram a burocracia estatal, transformando os espaços de participação - incluindo os Conselhos Gestores - em medidas e políticas públicas concretas que possibilitem uma melhora na qualidade de vida da população.

Sob outra perspectiva, Carneiro (2002) trata da relação entre conselhos e Estado, enfatizando a dicotomia existente entre a autonomia e a dependência frente a esse governo, que precisa reconhecer a relevância do trabalho desenvolvido para que elas funcionem. Assim, para a efetivação do potencial de emancipação dos conselhos, faz-se necessário uma "sociedade civil organizada e capaz de exercer influência sobre o sistema político e sobre as burocracias públicas, fortalecendo a dimensão associativa da cidadania" (CARNEIRO, 2002).

Além do grau de indução e permeabilidade do poder público municipal às demandas e aos canais de deliberação existentes, conforme elenca Carneiro (2002), a efetiva atuação dos conselhos depende também de outros fatores, notadamente a movimentação da vida associativa e participativa local e o total de capital social disponível e em uso. Assim, indubitavelmente, existem muitas barreiras a serem superadas para que os conselhos efetivem seu papel ao viabilizar maior participação e o controle social.

\section{MATERIAIS E MÉTODOS}

O artigo, de cunho qualitativo e descritivo, objetivou compreender a forma de atuação dos conselhos gestores de políticas públicas do município de Viçosa-MG, diante do cenário de pandemia da Covid-19. Assim, realizado no período de maio a julho de 2020, este estudo buscou identificar e analisar as ações executadas e, sob a perspectiva dos entrevistados, a efetividade delas acrescidas dos desafios enfrentados. Segundo Gil (2002) a pesquisa descritiva pretende descrever um fenômeno e/ou verificar a relação entre variáveis. Este tipo de pesquisa é usado para definir novos métodos e maneiras de se solucionar problemas específicos 
(OECD, 1993, citado por CASARIN, 2012).

Quanto ao universo do estudo, este foi composto pelo número total de conselhos gestores de políticas públicas municipais ativos, qual seja 19. É mister destacar que a pesquisa não envolveu os conselhos ativos em sua totalidade, em função da indisponibilidade ou dificuldade em contatar muitos membros dessas instituições. Dessa forma, a amostra foi composta por 15 conselhos tendo sido entrevistados 16 sujeitos, dentre os quais 15 eram responsáveis por presidir tais conselhos e 01 era responsável por representar uma instituição específica em um deles.

A coleta de dados, por sua vez, baseou-se em dados primários e a técnica utilizada para coleta desses dados foi a entrevista semiestruturada, a qual Triviños (1987) aponta como sendo o método onde se formula previamente perguntas sobre o tema abordado no intuito de balizar e nortear o contato com os sujeitos a serem entrevistados. Tais questionamentos se apoiam em teorias e hipóteses relacionados à problemática abordada e acarretam o surgimento de novas hipóteses com base nas respostas obtidas. Dessa forma, além de demandar uma postura ativa do pesquisador, a entrevista semiestruturada "favorece não só a descrição dos fenômenos sociais, mas também sua explicação e a compreensão de sua totalidade" (TRIVIÑOS, 1987).

Partindo de tal definição, as entrevistas realizadas com os conselheiros tiveram algumas questões elaboradas para compor seu roteiro, visando atender aos objetivos do estudo. Cabe ressaltar, no entanto, que, assim como o momento atual tem impactado em frentes diversas, ele impactou a realização da própria pesquisa onde, devido às determinações de reclusão e distanciamento social, as entrevistas não puderam ser realizadas presencialmente, tendo sido adotada a utilização de recursos virtuais - como WhatsApp e Google Meet. Ademais, quanto às limitações intrínsecas à obtenção de dados, com potencial para enviesar a pesquisa, podemos citar o desconforto ou falta de motivação para colaborar da melhor forma por parte dos sujeitos pesquisados e, ainda, os ruídos na comunicação oriundos dos próprios recursos adotados e, possivelmente, da subjetividade dos respondentes em algum momento das entrevistas.

Já no que se refere à análise e interpretação dos dados, foi utilizada a análise de conteúdo, definida por Bardin (1977) como:

Um conjunto de técnicas de análise das comunicações visando obter, por procedimentos sistemáticos e objetivos de descrição do conteúdo das mensagens, indicadores, quantitativos ou não, que permitam a inferências de conhecimentos relativos às condições de produção/recepção (variáveis inferidas) destas mensagens. (BARDIN, 1977)

Por fim, sobre a aplicação da técnica, definiu-se categorias em função dos objetivos e, consequentemente, das perguntas elencadas no roteiro das entrevistas. Dessa forma, os achados da pesquisa foram agrupados em três tópicos, adiante listados e descritos na próxima seção: Ações dos Conselhos Gestores para o enfrentamento da Covid-19; Efetividade dos Conselhos Gestores em cenário de Pandemia; e Desafios observados.

\section{RESULTADOS E DISCUSSÃO}

O estudo envolveu 15 conselhos gestores de políticas públicas ativos e de áreas específicas e naturezas diversas, relacionados no Quadro 1. Partindo do pressuposto, abordado por Cortes (2011), de que 
a área de atuação política influencia a composição e atuação do conselho gestor, compreende-se a diversidade de questões potenciais a serem apontadas, sendo mister destacar que não se tem, nesta pesquisa, a pretensão de abarcar todas as singularidades próprias dessas realidades. Assim, este tópico concede atenção especial a pontos compartilhados e, também, convergentes relatados pelos representantes das instituições participantes do estudo e observados pelos pesquisadores.

Quadro 1: Conselhos Gestores do Município de Viçosa-MG.

\begin{tabular}{|l|l|l|l|l|}
\hline NOME & SIGLA & $\begin{array}{l}\text { REPRES. } \\
\text { GOVERNO }\end{array}$ & $\begin{array}{l}\text { REPRES. } \\
\text { CIVIL }\end{array}$ & $\begin{array}{l}\text { SOC. } \\
\text { TOTAL } \\
\text { REPRES. }\end{array}$ \\
\hline Conselho de Alimentação Escolar & CAE & 01 & 08 & 09 \\
\hline Conselho Municipal do Desenvolvimento Rural Sustentável & CMDRS & 08 & 19 & 26 \\
\hline Conselho Municipal de Assistência Social & CMAS & 05 & 05 & 10 \\
\hline $\begin{array}{l}\text { Conselho M. de Cultura e do Patrimônio Cultural e } \\
\text { Ambiental de Viçosa }\end{array}$ & CMCPCAV & 13 & 12 & 25 \\
\hline Conselho Municipal Antidroga & COMAD & 09 & 09 & 18 \\
\hline Conselho Municipal de Educação & CME & 08 & 13 \\
\hline Conselho Municipal de Política Cultural & CMPC & 10 & 05 & 20 \\
\hline Conselho Municipal de Saúde & CMS & 14 & 10 & 28 \\
\hline Conselho Municipal do Idoso & CMI & 05 & 14 & 11 \\
\hline $\begin{array}{l}\text { Conselho Municipal dos Direitos da Criança e do CMDCA } \\
\text { Adolescente }\end{array}$ & & 06 & 06 & 12 \\
\hline Conselho Municipal dos Direitos da Mulher & CMDM & 06 & 06 & 12 \\
\hline Conselho Municipal dos Direitos da Pessoa com Deficiência & CMDPD & 06 & 06 & 12 \\
\hline Conselho Municipal do FUNDEB & - & 08 & 06 & 13 \\
\hline Conselho Municipal do Orçamento Participativo & CMOP & 05 & 05 & 10 \\
\hline Conselho Municipal do Turismo & CMT & 05 & 05 & 10 \\
\hline
\end{tabular}

Cortes (2011) constata em sua pesquisa que a maioria dos conselhos gestores promove encontros regulares, o que é corroborado pelos resultados deste estudo, onde se observa que a quase totalidade deles, em condições ditas "normais", se reúne mensalmente, com a possibilidade de convocações extraordinárias. A exceção se observa quanto ao Conselho Municipal do Turismo, cujas sessões se dão apenas trimestralmente. Contudo, no contexto específico de isolamento e distanciamento social oriundo da pandemia da Covid-19, os encontros presenciais estão temporariamente suspensos, sendo substituídos pela realização de reuniões virtuais.

Também como resultado das entrevistas realizadas, tem-se que a composição desses conselhos, que possuem quantitativos distintos de membros, se dá, em geral, de forma autônoma para os representantes não-governamentais, com eleições e indicações das entidades representadas, e com livre nomeação pelo poder público municipal de seus respectivos representantes. Mas, embora tenha-se identificado, como exposto no Quadro 1, que essas composições atendem aos critérios regulamentares de paridade, tal característica, como destacado por Cortes (2011), não é suficiente para alicerçar discussões sobre a efetividade desses espaços, sendo importante considerar também a forma de atuação e as ações desenvolvidas, inclusive no contexto atual onde arranjos e rotinas especiais são estabelecidos e novos papéis são adotados.

\section{Ações dos Conselhos Gestores para o enfrentamento da Covid-19}

Diante da natureza multidimensional das crises epidemiológicas de grandes proporções, são 
re-queridas medidas que abarquem diferentes áreas, como saúde, economia, mercado de trabalho, infraestrutura, mobili-dade urbana, questões sanitárias, logísticas e sociais de ordem mais ampla (SCHMIDT et al., 2020). Nesse sentido, e dada a especificidade de cada Conselho Gestor, os entrevistados fizeram menções diversificadas quanto as ações dos conselhos para o enfrentamento da pandemia da Covid-19.

Foram relatadas pelos entrevistados desde práticas relacionadas à divulgação de notícias e instruções, visando sensibilização e conscientização, até atuações voltadas para a realização de campanhas de doação, bem como ao atendimento médico de casos suspeitos e confirmados. Cumpre destacar que, além de ações específicas relacionadas à pandemia, todos os entrevistados, inclusive os que não veem as instituições que representam com atuação direta no que tange ao enfrentamento, compreendem a importância de observar as ações protetivas, conforme orientação das autoridades sanitárias nacionais e internacionais, e de "dar o exemplo" para os cidadãos no que se refere ao cumprimento das determinações, em especial as de reclusão e distanciamento social, com consequente suspensão de reuniões e demais atividades presenciais.

No que tange às ações especificamente desenvolvidas visando o enfrentamento da pandemia da Covid-19, foram relatadas as ações constantes no Quadro 2.

Quadro 2: Ações desempenhadas por conselhos gestores do município de Viçosa-MG.

\begin{tabular}{|c|c|}
\hline CONSELHOS & AÇÕES \\
\hline CMDCA & $\begin{array}{l}\text { Parceria com instituições públicas e privadas, para fornecimento de orientações à comunidade, em especial as } \\
\text { crianças e adolescentes (conselheiros tem dado entrevistas para rádios, jornais e TV) e realização de } \\
\text { campanhas para arrecadação de alimentos e agasalhos destinados a famílias carentes. }\end{array}$ \\
\hline $\mathrm{CMI}$ & $\begin{array}{l}\text { Realização de um plano de trabalho, em conjunto com a Secretaria de Assistência Social, visando acompanhar } \\
\text { os idosos em situação de risco social, fazendo um levantamento do que necessitam (como, por exemplo, cestas } \\
\text { básicas, consultas médicas, troca de receitas, entre outros). Além de atuar no aconselhamento e realização de } \\
\text { campanhas de orientação. }\end{array}$ \\
\hline CMDPD & $\begin{array}{l}\text { Divulgação, através de mídias sociais, de materiais voltados para a importância de atenção à higienização, ao } \\
\text { uso de máscara, ao isolamento social, bem como ao cumprimento das orientações advindas das esferas } \\
\text { municipais, estaduais, e federais no que tange ao Covid-19. }\end{array}$ \\
\hline CAE & $\begin{array}{l}\text { Apoio às famílias dos alunos das escolas municipais, com auxílio e distribuição de cestas básicas às famílias dos } \\
\text { alunos, além da disponibilização de materiais com informações sobre os cuidados higiênicos, durante a } \\
\text { pandemia, e de máscaras com informações de uso. }\end{array}$ \\
\hline CMS & $\begin{array}{l}\text { Criação do comitê específico para a Covid -19 (COES) e participação nas deliberações de suas ações. Houve } \\
\text { destaque, nesse tópico, para o papel de instituições que fazem parte do conselho, quais sejam os hospitais, } \\
\text { que estão desempenhando funções extremamente importantes de acolhimento, direcionamento, } \\
\text { atendimento e suporte à população da cidade, inclusive com adaptações nas estruturas físicas, reestruturação } \\
\text { na aquisição de EPIs, e disponibilização de UTI exclusivo para pacientes com Covid-19, como é o caso do } \\
\text { Hospital São João Batista. Junto a essas ações, é também citado o suporte fornecido pela universidade, com } \\
\text { atuação de destaque nas medidas de enfrentamento, e pelos planos de saúde da cidade, que fizeram um } \\
\text { aporte importante de recurso para aquisição de EPI. }\end{array}$ \\
\hline CME & $\begin{array}{l}\text { Mobilização para discutir as medidas de manutenção da suspensão das atividades escolares e, também, as } \\
\text { medidas a serem adotadas após o retorno. }\end{array}$ \\
\hline CMOP & $\begin{array}{l}\text { Acompanhamento, fiscalização e apreciação da implementação de ações, realizadas pela prefeitura, e } \\
\text { relacionadas ao Covid-19 (como recebimento de algum recurso do governo federal e aprovação de planos). }\end{array}$ \\
\hline CMAS & $\begin{array}{l}\text { Fornecimento de auxílio, junto à equipe técnica, para a Secretaria de Assistência Social, visando } \\
\text { regulamentação dos critérios para concessão dos benefícios do auxílio alimentação e para a forma de sua } \\
\text { solicitação, no contexto atual; disponibilização de um ramal para contato com a Secretaria, em caso de } \\
\text { necessidade; montagem e entrega, segundo o respondente } 6 \text {, de mais de } 3 \text { mil cestas básicas, adquiridas com } \\
\text { um montante que engloba recursos próprios e recursos vinculados a campanhas de doação; e distribuição de } \\
\text { máscaras. O conselho mencionou, ainda, a aprovação de um plano de contingência da Secretaria Municipal, } \\
\text { em decorrência da Covid-19, e a contribuição na elaboração de resolução que dispõe acerca do atendimento } \\
\text { do cadastro único para programas sociais do governo federal. }\end{array}$ \\
\hline $\begin{array}{l}\text { CM do FUNDEB, } \\
\text { CMDRS e CMT }\end{array}$ & $\begin{array}{l}\text { No momento da pesquisa, se encontravam em fase de realização de reuniões virtuais para proposição de } \\
\text { ações. }\end{array}$ \\
\hline
\end{tabular}


As referidas ações evidenciam a atenção dada e a importância dos conselhos gestores neste cenário atual de pandemia seguindo, contudo, a mesma lógica de gestão setorizada, que mantém a atuação com a política setorial ao qual se encontra vinculado sem a considerável realização de trabalhos em conjunto.

Ainda assim, os conselhos demonstram latente preocupação no que tange à atuação preventiva, de cunho educativo - com disponibilização de materiais de orientação, fornecimento de entrevistas em matérias veiculadas por canais de comunicação, como rádios. Nota-se, também, uma atuação assistencialista, com realização de campanhas solidárias como, por exemplo, de montagem, arrecadação e distribuição de cestas básicas para famílias carentes. Em frentes mais específicas, como no caso do Conselho Municipal de Saúde, são percebidos esforços preventivos no tocante a seu quadro de colaboradores, e remediativos quanto ao atendimento e tratamento de pacientes suspeitos e/ou confirmados com Covid-19.

No entanto, para que as importantes ações desempenhadas pelos conselhos gestores tenham êxito, faz-se necessário estabelecer comunicação com a sociedade interessada. Neste sentido, ao buscar compreender os meios de comunicação utilizados e as formas de aproximação dos conselhos com a sociedade, tanto para tornar as suas ações transparentes, como para apoiá-la e fazer a intermediação para solucionar problemas decorrentes da pandemia da Covid-19, identificou-se: iniciativas de disponibilização de informações educativas, por meio de mídias sociais e canais de comunicação como programas de rádios; realização de reuniões virtuais abertas à participação da comunidade; e divulgação de informações pontuais e cotidianas de alguns conselhos. Assim, aponta-se uma modesta exploração das capacidades dos meios digitais, com restrito conteúdo dos conselhos disponível tanto nos sítios eletrônicos oficiais quanto nas mídias sociais. Neste caso, seria crucial: garantir instâncias formais e canais de comunicação permanentes; definir interlocutores responsáveis por orientar, dialogar e manter informada a comunidade sobre as medidas adotadas, e em discussão, para o enfrentamento da crise; e determinar a periodicidade e frequência de tal comunicação (SCHMIDT et al., 2020).

É imperioso destacar que, apesar de parte dos resultados não serem necessariamente perceptíveis em períodos curtos de tempo, conforme abordam Schmidt et al. (2020), não investir em ações de enfrentamento contribui para aprofundar e fortalecer os fatores responsáveis por influenciar a reprodução das vulnerabilidades já existentes na sociedade brasileira nas mais diversas dimensões. Lembrando que, uma mobilização neste sentido teria potencial para aproximar a população dos conselhos, despertar maior interesse sobre sua atuação, além de evitar a assimetria e o desencontro de informações, podendo reduzir os problemas ambíguos advindos de um alto grau de dinamismo e um baixo nível de informações completas e confiáveis, além de graus elevados de tensão social, típicos de situações de crises emergenciais, como a que foi deflagrada pela pandemia da Covid-19.

\section{Efetividade dos Conselhos Gestores em cenário de Pandemia}

Sobre a efetividade alcançada pelos conselhos gestores no desempenho de suas ações de enfrentamento à pandemia da Covid-19, as sinalizações por parte dos entrevistados, conforme se nota no Gráfico 1, não foram consensuais, com destaque para o fato de nenhum deles considerar inefetivo o conselho 
que representa.

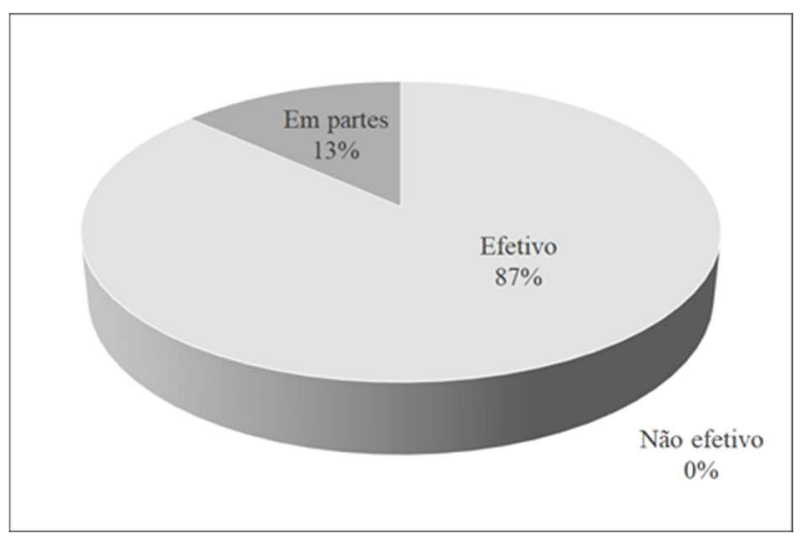

Gráfico 1: Efetividade na execução das ações.

Com ressalvas para as dificuldades enfrentadas e melhor abordadas no tópico subsequente, a efetividade defendida por $87 \%$ dos respondentes foi embasada: nos esforços dos conselheiros para que as atividades não cessassem nesse novo contexto; nas aprovações, por meio de resoluções, para o envio de recursos pelos governos federal, estadual e municipal para combate do Covid-19, possibilitando a consecução das ações; no acompanhamento remoto de prestações de contas e folhas de pagamento dos servidores municipais; e na atuação que antecedeu a pandemia e fortaleceu as bases dessas instituições.

Já como forma de argumentar a posição de que os conselhos não têm sido totalmente efetivos no desempenho de seus papéis ( $13 \%$ dos respondentes), foram elencados o fato de não estarem ocorrendo alguns repasses de recursos oriundos do governo estadual, além de questões relacionadas à pouca habilidade de alguns conselheiros para com os meios digitais, o que acaba por impactar a realização remota de reuniões, comprometendo a efetividade no desempenho das ações.

A despeito da complexidade de se discutir sobre a efetividade deliberativa (VAZ, 2011), e se atendo à percepção dos respondentes sobre a o tema, as ações executadas pelos conselhos para o enfrentamento da pandemia podem ser consideradas, em sua maioria, efetivas. Todavia, como apontado por Schmidt et al. (2020), considerar as estratégias que visem coordenar as ações; evitar dispersão e fragmentação com medidas pontuais e isoladas; além de evitar sobreposição de ações com escopos similares - com consequente desperdício de recursos humanos, burocráticos e financeiros - facilita a percepção de um panorama mais amplo sobre a efetividade, ou não, da atuação dessas instituições que, além dos percalços normalmente enfrentados, se encontram cercadas de novos desafios.

\section{Principais desafios observados}

Dentre os esperados impactos no âmbito político, econômico e, principalmente, nos sistemas de saúde, próprios de um momento como o atual, as instituições pesquisadas elencaram os desafios, entendidos como principais, quando da execução de suas atividades.

Na tentativa de agrupá-los, temos os desafios de ordem financeira: atrasos nos repasses; cortes nos salários dos servidores da educação; limitação de recursos, de pessoal e de estrutura; "falta de recursos do Poder Municipal para implementar maiores ações e, como as ações são conjuntas, interferem nos objetivos 
do Conselho" (RESPONDENTE 1). Diante desses investimentos, seria possível "contribuir com a administração pública na conscientização das pessoas, [pois] muitas delas não cumprem as orientações do Ministério da Saúde, e dos órgãos estaduais e municipais, por falta de instrução" (RESPONDENTE 9).

Sob a ótica das frentes com ações solidárias, um grande desafio está em fazer um cadastro real de todas as famílias necessitadas; conseguir recursos para que tenha quantidade suficiente de cestas básicas, não dependendo exclusivamente de doações nesse momento de ampliação do desemprego e vulnerabilidade social; e:

“[...] uma outra preocupação, que é também um desafio para nós, é que haja uma centralidade de quem faz essa distribuição [de cestas básicas], para a gente não ter famílias que não receberam ou famílias que receberam mais de uma vez, uma vez que a própria sociedade civil organizada, as igrejas ou outros órgãos fazem esse tipo de ação e pode ser duplicado com a Secretaria. Assim, o conselho tem pedido muito para sempre reportar à Secretaria, como um controle para que a gente não tenha duplicidade de ações" (RESPONDENTE 6).

Tal visão vai ao encontro ao exposto por Schmidt et al. (2020), sobre a proliferação de medidas implementadas por múltiplos atores em diferentes tempos, sem esforços mínimos de coordenação, ampliar consideravelmente a chance de sobreposição de ações, desperdícios de recursos de toda natureza, lacunas de atendimento ou eficácia das medidas implantadas.

Outra categorização possível em termos de desafio se dá pela ótica da comunicação entre membros e entre conselho e comunidade, sendo necessário estabelecer um meio de comunicação alternativo e eficaz para debater suas questões: "dificuldade em reunir todas as pessoas e fazer com que os órgãos públicos atendam as demandas" (RESPONDENTE 5); pouca intimidade de muitos membros com tecnologia, para o trabalho remoto, e mídias sociais; e "fazer a informação chegar até o idoso nas redes sociais" (RESPONDENTE 7). Estes relatos seguem na linha da comunicação e corroboram com as discussões anteriores sobre a importância de um canal coordenado e estrategicamente pensado (SCHMIDT et al., 2020).

Ademais, obter expressiva participação social figura entre os desafios em função da dificuldade dos conselhos em cumprir sua atuação em um cenário desfavorável e garantir seu papel de auscultar a população de forma maciça: “É importante dizer: se já tivéssemos uma tradição de participação popular (...) seria mais tranquilo, mais factível de acontecer. Mas é um processo que estamos iniciando, então estamos estudando uma forma mais pedagógica de envolver as pessoas" (RESPONDENTE 8).

Por fim, em outra perspectiva, foram apresentados desafios específicos das áreas como, por exemplo, dificuldade de atender demandas do turismo, que teve suas atividades diretamente afetadas pelo cenário atual; e falta de EPI no mercado para os que trabalham na linha de frente do enfrentamento à pandemia.

De forma geral, vislumbra-se, em consonância com o exposto por Schmidt et al. (2020), que uma maior coordenação, convergência e complementaridade nas ações dos conselhos, com alinhamento de tarefas e esforços, facilitaria a organização dessas instituições na busca por superar tanto os desafios elencados, quanto outros que possam e devam surgir. 


\section{CONCLUSÕES}

Com o atual cenário de pandemia da Covid-19, o decorrente agravo da instabilidade política vivenciada no Brasil e os aspectos financeiros já antes limitantes da administração pública, mudou-se a forma de atuação dos conselhos gestores do município de Viçosa-MG, que além de se adequarem para a utilização das tecnologias que lhes permitiram permanecerem ativos, se viram diante da necessidade de reagir e atuar de forma propositiva no enfrentamento da doença e na assistência à sociedade, em especial às pessoas e famílias em situação de vulnerabilidade.

A partir do estudo, foram notados esforços por parte dos conselhos no sentido de manter as atividades em andamento, na medida do possível, realizando adaptações, flexibilizações e adotando alternativas virtuais não usualmente cogitadas. Identificou-se, ainda, iniciativas originárias do atual contexto e para ele apropriadas como, por exemplo, medidas de cunho educativo, com campanhas de orientação, prevenção e conscientização para a comunidade; medidas também de cunho assistencial - campanhas solidárias - e ações remediativas, como o atendimento e suporte prestado pela área da saúde. Essa atual realidade possibilitou aos conselheiros uma nova perspectiva sobre suas ações em que, muitos deles, consideram a possibilidade, viabilidade e, até mesmo, a necessidade de se manter, no pós-pandemia, algumas das medidas adotadas para esse momento, como medidas sanitárias de segurança, principalmente no caso da saúde; opções virtuais de entretenimento, como no caso da cultura; e também manter e ampliar as iniciativas de assistência para as famílias mais vulneráveis, dentre outras.

No entanto, o estudo também apontou para a ausência de uma expressiva coordenação, convergência e complementaridade das atividades, sinalizada por iniciativas pontuais e, por vezes, similares desenvolvidas em conselhos distintos e sem integração entre eles; além de uma modesta disponibilização de conteúdo em sítios eletrônicos oficiais e mídias sociais, indicando um subaproveitamento de todo potencial desses canais que são cada vez mais utilizados pela população e podem contribuir para a participação social nestes espaços que visam promovê-la, especialmente neste contexto de isolamento e distanciamento social.

Em suma, identificou-se que, no contexto estudado, os desafios se multiplicam para os conselhos, vez que eles devem se posicionar e mobilizar uma busca por esforços coordenados e alinhamento de sua atuação com o governo, rompendo com a intersetorialidade e garantindo o cumprimento de seu papel de aproximar poder público e comunidade. Há também o desafio de implementar canais de comunicação e de prestação de contas que possam agregar ao fortalecimento de arranjos democráticos de gestão, além de causar um efeito de acolhimento, ainda que não em sua totalidade, das demandas apresentadas pela população. A adequada coordenação das ações poderia, ainda, otimizar a utilização dos enfatizados recursos escassos; possibilitar maior atenção à capacitação devida aos conselheiros para o desempenho cotidiano de seus papéis; e aumentar as chances de se obter qualidade e efetividade na atuação, sob a perspectiva tanto dos próprios conselhos e do poder público, quanto da comunidade, promovendo e fortalecendo um elo que facilitaria a superação dos inevitáveis desafios existentes em situações que se apresentem - ou não - como crises emergenciais. 
Importa frisar que inicialmente pretendia-se trabalhar também com dados secundários, visando obter maior profundidade sobre as ações desenvolvidas pelos Conselhos Gestores Viçosenses durante a pandemia do novo coronavírus. Contudo, ao realizar as buscas em sites e mídias digitais, o que se viu foi a ausência de informação por parte dos Conselhos, com raras exceções para o Conselho Municipal de Saúde, o que traria um foco específico, que não era o intuito deste estudo. Ademais, pode-se citar a exclusiva participação dos responsáveis pelos conselhos como limitante à pesquisa vez que, em função do recorte adotado e do próprio contexto da pandemia, a visão dos que usufruem de tais serviços não foi apurada.

Por fim, considerando que vários autores têm discutido a importância da participação virtual para o desenvolvimento da democracia, tendo como mecanismos a Internet, as mídias sociais e a velocidade no tráfego de informações, abre-se, assim, um leque para futuras pesquisas ligadas à accountability como forma de prestação de contas dos conselhos gestores da cidade de Viçosa-MG e também sobre o canal de comunicação entre conselhos e sociedade, para que, em tempos de crise como a atual, as informações cheguem mais rapidamente para a sociedade e favoreçam o controle social.

\section{REFERÊNCIAS}

ARANTES, R. B.; LOUREIRO, M. R.; COUTO, C.; TEIXEIRA, M. A. C.. Controles democráticos sobre a administração pública no Brasil: Legislativo, tribunais de contas, Judiciário e Ministério Público. In: LOUREIRO, M. R.; ABRUCIO, F.; PACHECO, R.. Burocracia e política no Brasil: desafios para o Estado democrático no século XXI. Rio de Janeiro: FGV, 2010.

BARDIN, L.. Análise de Conteúdo. Lisboa: Edições 70, 1977.

BORBA, J.. Participação Política como Resultado das Instituições Participativas: oportunidades políticas e o perfil da participação. In: PIRES, R. R. C.. Efetividade das instituições participativas no Brasil: estratégias de avaliação. Brasília: IPEA, 2011. p.65-76.

BRASIL. Constituição Federal de 1988. Promulgada em 5 de outubro de 1988. Brasília: DOU, 1988.

CAMPOS, A. M.. Accountability: quando poderemos traduzila para o português?. Revista de Administração Pública, v.24, n.2, p.30-50, 1990.

CARNEIRO, C. B. L.. Conselhos de políticas públicas: desafios para sua institucionalização. Revista de Administração Pública, v.36, n.2, p.277-292, 2002.

CASARIN, H. C. S.. Pesquisa científica: da teoria à prática. Curitiba: InterSaberes, 2012.

CORTES, S. V.. As Diferentes Instituições Participativas Existentes nos Municípios Brasileiros. In: PIRES, R. R. C. Efetividade das instituições participativas no Brasil: estratégias de avaliação. Brasília: IPEA, 2011. p.137-150.

CUNHA, E. S. M.. Aprofundando a democracia: o potencial dos conselhos de políticas e orçamentos participativos. Dissertação (Mestrado em Ciência Política) - Universidade Federal de Minas Gerais, Belo Horizonte, 2004.
FARIA, C. F.; RIBEIRO, U. C.. Desenho Institucional: variáveis relevantes e seus efeitos sobre o processo participativo. In: PIRES, R. R. C.. Efetividade das Instituições Participativas no Brasil: estratégias de avaliação. Brasília: IPEA, 2011. p.126137.

FONSECA, I. F.. Relações de poder e especificidades do contexto em fóruns participativos. In: PIRES, R. R. C.. Efetividade das instituições participativas no Brasil: estratégias de avaliação. Brasília: IPEA, 2011. p.159-170.

GIL, A. C.. Como elaborar projetos de pesquisa. São Paulo, v.5, n.61, p.16-17, 2002.

MENEZES, J. B.. A participação popular como fonte de legitimidade democrática da administração pública. In: CONGRESO INTERNACIONAL DEL CLAD SOBRE LA REFORMA DEL ESTADO Y DE LA ADMINISTRACIÓN PÚBLICA, 10. Anais. Santiago, 2005. p.18-21.

NOBRE, A.. Democracia, cidadania e participação social: uma estreita relação. Emancipação, n.7, n.2, p.209-226, 2007.

PEREIRA, R. M.; ROBERTO, R. F.; GAVA, R.; SILVA, E. A.. Conselhos gestores de políticas públicas: relações entre estado e sociedade civil no contexto local. Revista de Gestão em Sistemas de Saúde, v.5, n.1, p.29-40, 2016.

PINHO, J. A. G.; SACRAMENTO, A. R. S.. Accountability: já podemos traduzi-la para o português?. Revista de Administração Pública, v.43, n.6, p.1343-1368, 2009.

ROCHA, E.. A Constituição cidadã e a institucionalização dos espaços de participação social: avanços e desafios. In: VAZ, F. T.; MUSSE, J. S.; SANTOS, R. F.. 20 anos da constituição cidadã: avaliação e desafios da seguridade social. Brasília: ANFIP, 2008. p.131-148.

SCHMIDT, F.; MELLO, J.; CAVALCANTE, P.. Estratégias de coordenação governamental na crise da Covid-19. Diretoria 
de Estudos e Políticas do Estado, das Instituições e da Democracia. Nota Técnica. IPEA, 2020.

TRIVIÑOS, A. N. S.. Introdução à pesquisa em ciências sociais: a pesquisa qualitativa em educação. São Paulo: Atlas, 1987.

VAZ, A. C. N.. Da participação à qualidade da deliberação em fóruns públicos: o itinerário da literatura sobre conselhos no
Brasil. In: PIRES, R. R. C.. Efetividade das instituições participativas no Brasil: estratégias de avaliação, Brasília: IPEA, 2011. p.91-108.

WAMPLER, B.. Instituições participativas como "enxertos" na estrutura do Estado: a importância de contextos, atores e suas estratégias. In: PIRES, R. R. C.. Efetividade das instituições participativas no Brasil: estratégias de avaliação, Brasília: IPEA, 2011. p.151-158.

A CBPC - Companhia Brasileira de Produção Científica (CNPJ: 11.221.422/0001-03) detém os direitos materiais desta publicação. Os direitos referem-se à publicação do trabalho em qualquer parte do mundo, incluindo os direitos às renovações, expansões e disseminações da contribuição, bem como outros direitos subsidiários. Todos os trabalhos publicados eletronicamente poderão posteriormente ser publicados em coletâneas impressas sob coordenação da Sustenere Publishing, da Companhia Brasileira de Produção Científica e seus parceiros autorizados. Os (as) autores (as) preservam os direitos autorais, mas não têm permissão para a publicação da contribuição em outro meio, impresso ou digital, em português ou em tradução. 